\title{
UMA PERSPECTIVA CÉTICA QUANTO AO VALOR ABSOLUTO DOS DIREITOS HUMANOS
}

A SKEPTICAL VIEW ON THE ABSOLUTE VALUE OF HUMAN RIGHTS

UNA PERSPECTIVA ESCÉPTICA EN CUANTO AL VALOR ABSOLUTO DE LOS DERECHOS HUMANOS

\section{André Luiz Olivier da Silva ${ }^{1}$}

Resumo: O presente trabalho aponta para uma das teses mais confusas acerca da fundamentação dos direitos humanos, que consiste na afirmação de que esses direitos são direitos morais a priori e universais, isto é, são direitos absolutos. Mas o que significa dizer que os direitos humanos são absolutos? Segundo os programas tradicionais de fundamentação, os direitos humanos seriam direitos inatos à natureza humana e válidos para toda humanidade, independente de sua existência como direito positivo dentro de um ordenamento jurídico. A afirmação da universalidade dos direitos humanos tem suas raízes tanto no discurso moderno do direito natural quanto no discurso kantiano do valor absoluto. Em ambos os projetos, verifica-se uma metodologia que deduz direitos a partir de uma base metafísica segundo a qual os direitos humanos "devem ser" universais e válidos para todos os seres racionais. Como alternativa a esse tipo de leitura metafísica, o presente artigo propõe uma abordagem cética dos direitos, segundo a qual não há justificativa racional para dizer quais devem ser os direitos humanos. A partir de uma metodologia descritivista, pretende-se destacar que, em uma investigação filosófica sobre os direitos humanos, não se pode mais do que descrever o modo como as pessoas e os movimentos

1 Doutor em Filosofia e Professor dos Cursos de Graduação em Direito e Relações Internacionais da Universidade do Vale do Rio dos Sinos - UNISINOS, São Leopoldo, Rio Grande do Sul, Brasil. Bacharel em Filosofia e Direito; Advogado e, atualmente, Coordenador do Curso de Graduação em Direito da Unisinos. Endereço postal: Unisinos, Avenida Unisinos, 950, CEP 93022-000, São Leopoldo/RS. E-mail: andreluiz@unisinos.br 
de cunho social, moral e político nomeiam aqueles direitos que consideram humanos. Palavras-chave: direitos humanos - direitos morais - direitos naturais - universal - absoluto.

Abstract: This work highlights one of the most confusing theories about the foundation of human rights, which is the claim that these rights are a priori and universal moral rights, i.e. that they are absolute rights. But what does it mean that human rights are absolute? According to the traditional foundation programs, human rights are rights that are inherent to human nature, and are valid for all of humanity, regardless of their existence as positive law within a legal system. The affirmation of the universality of human rights has its roots in both modern discourse of natural law and the Kantian discourse about absolute value. In both projects, there is a methodology that infers rights on a metaphysical basis whereby human rights "should be" universal and valid for all rational beings. As an alternative to this kind of metaphysical reading, this article proposes a skeptical approach to the rights, whereby there is no rational justification to say what human rights should be. Based on a descriptivist methodology, this work aims to highlight that in an investigation of human rights, we can no longer describe the way in which people, and social, moral and political movements nominate those rights considered human rights. Keywords: human rights - moral rights - natural rights - universal - absolute.

Resumen: El presente trabajo apunta a una de las tesis más confusas acerca de la fundamentación de los derechos humanos, que consiste en la afirmación de que esos derechos son derechos morales a priori y universales, esto es, son derechos absolutos. Pero ¿qué significa decir que los derechos humanos son absolutos? Conforme los programas tradicionales de fundamentación, los derechos humanos serían derechos innatos a la naturaleza humana y válidos para toda la humanidad, independiente de su existencia como derecho positivo dentro de un orden jurídico. Las declaraciones de la universalidad de los derechos humanos tienen sus raíces tanto en el discurso moderno del derecho natural como en el discurso kantiano del valor absoluto. En ambos proyectos, se verifica una metodología que deduce derechos a partir de una base metafísica según la cual los derechos humanos "deben ser" universales y válidos para todos los seres racionales. Como alternativa a ese tipo de lectura metafísica, el presente artículo propone un enfoque escéptico de los derechos, según la cual no hay justificativa racional para decir cuáles deben ser los derechos humanos. A partir de una metodología descriptivista, se pretende destacar que, en una investigación filosófica sobre los derechos humanos, no se puede más que describir el modo en que las personas y los movimientos sociales, morales y políticos nombran esos derechos que consideran humanos. Palabras-clave: derechos humanos - derechos morales - derechos naturales - universal - absoluto. 


\section{INTRODUÇÃO}

A pós a Segunda Guerra Mundial, os programas teóricos de fundamentação dos direitos passaram a utilizar a linguagem dos direitos humanos para apontar e ressaltar a relação de alguns direitos com o fenômeno moral. Os direitos humanos seriam entendidos como direitos morais, isto é, direitos que não estariam necessariamente sujeitos a determinado ordenamento jurídico; considerados intrínsecos e inerentes à natureza humana; direitos que poderíamos exigir contra nossos governantes para assegurar a proteção da dignidade da pessoa humana. Embora o termo "direitos humanos" tenha surgido apenas no pós-guerra do século passado, os atuais projetos de fundamentação dos direitos nunca se desligaram do Iluminismo e do século XVIII. Eles se deixam influenciar profundamente pelas doutrinas dos direitos naturais e aceitam a tese de que podem existir direitos para além do ordenamento jurídico. Eles ainda estão comprometidos com uma fundamentação racionalista que visa à dedução de direitos absolutos e continuam a afirmar a tese de que alguns direitos possuem valor absoluto e podem ser considerados universais e válidos para toda humanidade.

Os direitos humanos são, em resumo, aqueles direitos morais que possuem valor "absoluto", ao menos esses direitos "são ditos como "absolutos"2 por pessoas e movimentos sociais, morais e políticos que visam garantir e efetivar aquilo que consideram ser um direito humano. Direitos absolutos são direitos universais. Conforme Cranston, são "os direitos de todas as pessoas em todos os momentos e em todas as situações"34. Nesse sentido, os objetivos do presente artigo consistem em: (a) analisar a tese de que os direitos humanos são direitos a priori e absolutos, tendo como base dois projetos modernos de fundamentação, a saber, as doutrinas dos direitos naturais e o discurso kantiano do valor absoluto; (b) mostrar que a tese do direito absoluto é consequência de uma confusão gerada pelos programas fundacionalistas que deduzem os direitos humanos a partir de uma base metafísica, segundo a qual esses direitos "devem ser" universais e

2 FEINBERG, Joel. Filosofia social. Tradução de Alzira Soares da Rocha e Helena Maria Camacho. Rio de Janeiro: Zahar, 1974. p. 85-86.

3 CRANSTON, Maurice. What are human rights? Tradução nossa. London: Bodley Head, 1973. p. 22.

4 Afirma Cranston: "Esta característica universal dos direitos humanos é uma grande parte do nosso problema na tentativa de justificá-los." (CRANSTON, Maurice. What are human rights? p. 22.). 
válidos para todos; e, por fim, (c) apresentar uma abordagem cética dos direitos humanos e, com base em uma metodologia descritiva, apontar para o modo como as pessoas e os movimentos de cunho social, moral e político classificam e nomeiam aqueles direitos que consideram mais importantes - os direitos humanos.

\section{O valor absoluto dos direitos morais}

Em que consiste um direito de caráter absoluto? - eis o problema sobre o qual pretendemos dissertar. O termo "absoluto" destaca não apenas que o direito é válido sempre e para todos os seres humanos dentro de um determinado limite ou contexto, mas, sim, que o direito é absoluto no sentido de universal. Quando pensamos em um direito humano, este é sempre tomado como um direito válido para todos de modo incondicional e sem exceções. Os direitos humanos constituem um tipo de direito "(...) igual para todos os seres humanos, incondicional e inalteravelmente" ${ }^{\prime \prime}$, conforme afirma Feinberg, ao destacar o sentido mais forte que a palavra "absoluto" pode adquirir: "(...) o de ser "absolutamente sem exceções", não apenas no âmbito de um escopo limitado, mas por todo um escopo ele próprio ilimitado." 6 . Assim, a principal característica desses direitos - característica esta que diferencia esses direitos dos direitos já existentes em um ordenamento jurídico - é que são atribuídos a todos os seres humanos, sem exceções, como se fossem direitos absolutos.

As afirmações sobre os direitos humanos são constituídas por asserções generalistas e universais, como se os direitos pudessem ser válidos para todos os seres humanos, em todas as épocas e em todos os lugares do universo, independente de uma promessa ou dos pequenos acordos que realizamos para produzir direitos especiais em um determinado contexto. Desde o senso comum até a linguagem erudita, os direitos humanos são considerados direitos gerais previamente dados na natureza; como se fossem universais, são aqueles direitos que todo e qualquer ser possuiria como humano, pelo simples fato de se reconhecer como um ser humano ou em razão de sua humanidade. Aliás, a "humanidade", ou o fato de sermos seres humanos e racionais, ou os mais variados sinônimos para termos como "razão" ou "racionalidade", fundamentariam os

6 FEINBERG, Joel. Filosofia social. p. 130. 
"nossos" direitos, transformando-nos, como em um passe de mágica, em ser humano detentor de direitos ou, até mesmo, em sujeito de dignidade. O ser humano, portanto, seria a pedra fundamental dos direitos morais humanos.

\subsection{A fundamentação dos direitos humanos}

No ímpeto de justificar e até mesmo legitimar a posse de um direito moral, os projetos de fundamentação dos direitos humanos costumam tropeçar em ilusões e deixam de observar como os direitos "são" para refletir e imaginar como eles "deveriam ser". A pretensão dos programas de fundamentação dos direitos é construir e inventar direitos a partir de razões deduzidas de uma capacidade racional dos seres humanos, como se fossemos seres superiores aos outros animais. Esses programas fundacionalistas pressupõem que a vida humana vale mais que a dos animais; que somos os únicos seres racionais e que, em vista disso, somos livres para deliberar e decidir o que fazer com a nossa própria liberdade individual. A partir desses pressupostos metafísicos, um programa fundacionalista deduz aqueles direitos que estão acima de todos os outros e os classifica como direitos humanos.

Esses programas pretendem "dar razões" acerca da existência de direitos morais, como é o caso dos direitos humanos; explicar as suas causas e motivos, deduzir e justificar os direitos a partir do homem, a partir de uma matriz racionalista - embora, no fundo, cada vez mais a discussão seja abocanhada por falsos argumentos racionalistas sob a ilusão de que estaremos, um dia, autorizados a dizer que as nossas crenças em relação aos direitos humanos possam ser, enfim, consideradas reais e objetivas, como se fôssemos realmente sujeitos com direitos intrínsecos à nossa própria natureza humana. Nessa seara, fala-se, então, em "fundamentação" dos direitos e apela-se a expressões mágicas, como "dignidade da pessoa humana", "autonomia da vontade", "interesse individual", dentre tantas outras expressões politicamente corretas que visam justificar os direitos humanos a partir de uma suposta capacidade racional universalizável e, portanto, válida para todos.

\subsection{A doutrina dos direitos naturais}

O primeiro grande tropeço que pode sofrer uma investigação sobre os 
direitos humanos é considerá-los sob a ótica dos direitos naturais ${ }^{7}$, que se resume a pressupor um título inato e inerente à pessoa, concedido por uma natureza racional, comum e igual a todos os homens; um título anterior a qualquer tipo de convenção, "redigido", digamos assim, pela mão de Deus ou em decorrência de uma natureza racional. Sob o pretexto dos direitos naturais, identificaríamos uma natureza anterior à sociedade, uma natureza que concede direitos intrínsecos à espécie humana, como se os direitos já nascessem dentro dos homens; como se fossem títulos universais e válidos para todos, sem distinção de raça, sexo, ou qualquer outro tipo de diferenciação.

Os direitos morais aos quais estamos a nos referir seriam, no fundo, direitos naturalmente inatos ao ser humano, seriam "direitos naturais" ${ }^{\text {, como se os }}$ direitos que estão contidos nas obrigações morais possuíssem características naturalmente dadas por um primeiro motor, por uma natureza racional ou, ainda, por um Deus criador. Tugendhat aponta a tradição dos direitos naturais como a primeira tradição dos direitos humanos:

Para acentuar o fato de que nos direitos morais se trata daqueles direitos que nós "temos", e que não apenas nos são concedidos por alguma ordem jurídica, a primeira tradição moderna dos direitos humanos têm falado de direitos naturais. ${ }^{9}$

Beitz ressalta, por seu turno, o dogma dos direitos naturais para a abordagem dos direitos humanos no mundo de hoje:

Acredito, no entanto, que a tendência para identificar os direitos humanos com direitos naturais representa uma espécie de dogmatismo filosófico inconsciente. Isso leva a um equívoco danoso sobre o escopo legítimo dos direitos humanos internacionais e do seu potencial para remediar a injustiça. Como a maioria dos dogmatismos, o primeiro desafio é reconhecê-lo pelo que ele é. E a melhor maneira de ver isto é olhar primeiro para os direitos humanos como eles realmente funcionam no mundo hoje e, em seguida, considerar se o paradigma dos direitos naturais é uma ajuda ou um obstáculo para se compreender o seu

7 Sobre os direitos naturais, consultar as seguintes referências: BROWN, 1955; CRANSTON, 1973; FRANKENA, 1955; FINNIS, 2007; HART, 1955; MACDONALD, 1946-47; NINO, 1989, p. 14; RITCHIE, 1998; STRAUSS, 1965.

8 Para Feinberg, os termos "direitos morais" e "direitos naturais" são compatíveis entre si, embora o termo "direitos morais" seja o mais aconselhável em razão do vínculo metafísico que a tese dos direitos naturais possui com aquelas características universais e imutáveis. Conferir: FEINBERG, Joel. In: Defense of Moral Rights. Oxford Journal of Legal Studies, Oxford, v. 12, n. 2, p. 153-154, 1992. Tradução nossa. Disponível em: <http://ojls. oxfordjournals.org/content/12/2/149.citation>. Acesso em: 17 mar. 2012.

9 TUGENDHAT, Ernst. Lições sobre ética. 5. ed. Petrópolis: Vozes, 2003. p. 344, grifos do autor. 
significado ético e político. ${ }^{10}$

Vários autores importantes caíram na cilada dos direitos naturais, como é o caso de Hart, em artigo de 1955, que chegou a arrolar "(...) a tese de que se existem direitos morais, segue-se que há pelo menos um direito natural, o direito igual de todos os homens serem livres." ${ }^{11}$. A afirmação condicional12 de Hart, de que, se existem direitos morais, esses devem ser naturais, explicita o direito igual a ser livre como um direito intrínseco à existência de todos os homens que são capazes de fazer escolhas em razão de sua própria vontade. $O$ direito à igualdade presente em "qualquer ser humano adulto capaz de uma escolha"13 se dedobra nos direitos de não sofrer interferências de terceiros ao praticar livremente uma ação.

De onde Hart extrai ou deduz esses direitos? Da mesma fonte onde foi beber e se embriagar a tradição moderna dos direitos naturais e do contrato social. Hart aponta duas razões para justificar o direito natural:

Tenho duas razões para descrever o direito igual de todos os homens serem livres como um direito natural; ambas foram sempre enfatizadas pelos teóricos clássicos dos direitos naturais. (1) Este direito é aquele segundo o qual todos os homens têm se são capazes de escolher; pois eles o têm qua homens e não apenas se forem membros de alguma sociedade ou por estarem em alguma relação especial entre si. (2) Esse direito não é criado ou conferido pela ação voluntária dos homens; outros direitos morais são. ${ }^{14}$

Por certo, Hart não pode ser considerado um defensor dos direitos naturais, mas não deixa de causar estranheza a sua arguição em prol dos direitos naturais. Hart está a defender a vontade e a capacidade de escolha do ser racional - que constituem, no fundo, os pontos em comum entre jusnaturalistas e kantianos. Diz Hart, ao colocar limites ao uso dessa capacidade de escolha:

10 BEITZ, Charles. What human rights mean. Daedalus, On International Justice, v. 132, n. 1, p. 38, winter 2003. Tradução nossa. Disponível em: <http://www.jstor.org/stable/20027821>. Acesso em: 12 jun. 2012.

11 HART, Herbert Lionel Alphonsus. 1955. Are There Any Natural Rights? The Philosophical Review, Duke University Press, v. 64, n. 2, p. 175, abr. 1955. Tradução nossa. Disponível em: <http://www.jstor. org/stable/2182586>. Acesso em: 12 fev. 2012.

12 Diz Hart: "Mas a minha afirmação de que existe esse direito natural, pode parecer insatisfatória em outro aspecto; é apenas a afirmação condicional de que se existem direitos morais, então deve haver esse direito natural." (HART, Herbert. Are There Any Natural Rights? p. 176, grifo do autor, tradução nossa.).

13 HART, Herbert. Are There Any Natural Rights? p. 175, grifo do autor, tradução nossa.

14 HART, Herbert. Are There Any Natural Rights? p. 175-176, grifos do autor, tradução nossa. 
É claro que é bastante óbvio que a minha tese não é tão ambiciosa como as teorias tradicionais de direitos naturais; porque, embora a meu ver todos os homens sejam igualmente entitulados a serem livres no sentido explicado, nenhum homem tem um direito absoluto ou incondicional para fazer ou deixar de fazer alguma coisa em particular ou para ser tratado de qualquer maneira particular; coerção ou restrição de qualquer ação pode ser justificada em condições consistentemente especiais com o princípio geral. ${ }^{15}$

Brown e Frankena são ainda mais influenciados pela tradição liberal ao defenderem direitos inalienáveis, "direitos naturais e inalienáveis"16; direitos "(...) à proteção daquilo que é do seu interesse."17, vendo, então, os direitos como "(...) direitos à proteção da vida, liberdade e busca da felicidade"18, direitos que "não podem moralmente ou logicamente ser renunciados, transmitidos e anulados." ${ }^{19}$. Brown retoma, então, a discussão iluminista sobre os direitos naturais, ao enfatizar o direito à proteção de todo homem:

Vou mostrar que os filósofos do século dezessete - e dezoito - estavam corretos ao considerar que existe um direito inalienável à proteção, mas incorretos em supor que esse direito à proteção é logicamente dependente dos direitos inalienáveis à vida, liberdade e felicidade. ${ }^{20}$

Margareth MacDonald também acolhe a tese dos direitos naturais, mas opta por uma via diversa da conjectura lógico-hipotética da natureza. Para ela, em razão da Segunda Guerra Mundial, os direitos humanos não passam de "(...) um apelo aos valores de liberdade e igualdade entre os homens"21, de modo que "(...) afirmações de valor são mais parecidas a registros sobre decisões do que proposições"22. Prossegue MacDonald: "Afirmar que "Liberdade é melhor do que escravidão" ou "Todos os homens são de igual valor" não é afirmar um fato,

15 HART, Herbert. Are There Any Natural Rights? p. 175-176, grifo do autor, tradução nossa.

16 FRANKENA, William K. Natural and inalienable rights. The Philosophical Review, v. 64, n. 2, p. 212, abr. 1955. Tradução nossa. Disponível em: <http://www.jstor.org/stable/2182588>. Acesso em: 30 mar. 2012.

17 BROWN, Stuart M. Inalienable Rights. The Philosophical Review, v. 64, n. 2, p. 192, abr. 1955. Tradução nossa Disponível em: <http://www.jstor.org/stable/2182587>. Acesso em: 18 maio 2012.

18 BROWN, Stuart M. Inalienable Rights. p. 192, grifo do autor, tradução nossa.

19 BROWN, Stuart M. Inalienable Rights. p. 192, tradução nossa.

20 BROWN, Stuart M. Inalienable Rights. p. 193, tradução nossa.

21 MACDONALD, Margaret. Natural Rights. Proceedings of the Aristotelian Society, New Series, v. 47, p. 226, 1946-1947. Tradução nossa. Disponível em: <http://www.jstor.org/stable/4544427>. Acesso em: 6 jun. 2012.

22 MACDONALD, Margaret. Natural Rights. p. 243 - 244, grifos do autor, tradução nossa. 
mas escolher um lado. Isso anuncia Aqui é o meu lugar." ${ }^{23}$. MacDonald, então, escolhe o lado edificante da razão humana, e, com isso, relaciona a razão com os direitos, mostrando que, conforme a tradição filosófica da linguagem dos direitos, estes são conhecidos por meio dos mecanismos racionais que governam a natureza humana:

Como podem os fatos sobre a natureza serem descobertos sem que nunca tenham sido observados ou confirmados pela observação? A resposta está no estatuto peculiar dado à razão na teoria. (...) Porque eles são conhecidos como provocados pela natureza intrínseca ou essencial do homem. Assim, eles são conhecidos pela razão. (...) A norma do direito natural é definida pela razão e é conhecida porque os homens têm razão. (...) ou seja, serem capazes de deduzir o ideal do real é um fato natural. (...) A razão é o grande nivelador ou elevador. ${ }^{24}$

Os direitos naturais já estariam previamente dados e careceriam, então, apenas de um esclarecimento, pois seriam autoevidentes e presentes no coração dos homens, como se bastasse apenas deduzir direitos de outros direitos, sob a guia de um procedimento racional-dedutivo que tem como ponto de partida o ser humano em um estado natural, o qual, por sua vez, servirá de fundamento para a formação dos primeiros direitos, os direitos mais básicos do ser humano. Afirma Ritchie: "O termo "direitos naturais" é geralmente restrito àqueles que são concebidos como mais fundamentais do que outros, a partir dos quais os outros podem ser deduzidos, ou para os quais os outros são apenas auxiliares"25. A partir da natureza do homem, os direitos mais naturais poderão gerar os direitos convencionados em uma legislação, justificando, assim, a sua existência perante o tribunal da razão.

Os direitos conferem, pois, boas razões para o seu possuidor agir e, dessa maneira, é possível dizer que o detentor do direito estaria autorizado à prática de uma atividade ao possuir uma razão, ou até mesmo ao possuir fortes razões não apenas para obstaculizar a ação dos outros, mas, sim, para exercer livremente o seu próprio direito - ao menos é isso o que podemos inferir da dogmática

23 MACDONALD, Margaret. Natural Rights. p. 244, grifos do autor, tradução nossa.

24 MACDONALD, Margaret. Natural Rights. p. 230 - 231, tradução nossa.

25 RITCHIE, David George. Natural rights: a criticism of some political and ethical conceptions. Tradução nossa. Bristol: Thoemmes Press, 1998. p. 80. 
dos direitos naturais. Segundo essa tradição, alguns direitos serviriam como a base para a formulação de outros direitos, em um movimento que vai do geral para o particular, em um pulo que parte dos direitos universais para os direitos contextuais e relativos a cada cultura.

\subsection{O discurso kantiano}

Os programas teóricos de direitos humanos fundados nos direitos naturais não estão sozinhos na empreitada de fundamentar direitos, pois, ao conceito de direito natural logo se junta outra tradição filosófica, que consiste em uma leitura enganadora dos direitos a partir do "valor absoluto" que Kant identificou no terreno da moralidade, conforme alerta Tugendhat: "Uma metáfora enganadora parecida com a dos direitos morais como direitos naturais é o discurso kantiano de um "valor absoluto" de todas as pessoas" 26 , uma metáfora que pressupõe a igualdade entre os homens, sem exceções, uma metáfora metafísica amparada na ideia totalizante de que lá no fundo não há distinção entre os seres humanos.

Quem defendeu a ideia de Kant do valor absoluto do ser humano foi Gregory Vlastos ${ }^{27}$, que, no artigo Justice and equality (1962), retomou a definição de justiça como igualdade estabelecida pelos gregos, em especial por Platão e Aristóteles, para mostrar que a moral moderna dos direitos humanos não pressupõe as disposições de caráter ou o "mérito" de cada homem para formular juízos morais, pois julga que todos eles são absolutamente iguais, sem exceções, independente de existirem no mundo homens bons ou cafajestes e canalhas. Todos merecem o mesmo tipo de tratamento.

Se retrocedermos aos antigos, veremos que a equidade está conectada com o desigual, ou seja, a distribuição da justiça pode se dar em conformidade com o mérito (desigual) de cada cidadão, que pode merecer mais do que os outros em determinados contextos. Nesse sentido, "(...) se 'igual' é sua palavra apenas para 'justo', você teria que dizer que uma distribuição 'igual' é algo desigual." 28 . Com base na leitura das doutrinas antigas do direito natural, Vlastos traz para

26 TUGENDHAT, Ernst. Lições sobre ética. p. 345.

27 Ver FEINBERG, Joel. Filosofia social. p. 89, e TUGENDHAT, Ernst. Lições sobre ética. p. 345. Tugendhat, na linha de Feinberg, destaca "o discurso kantiano de um "valor absoluto" de todas as pessoas recentemente assumido por G. Vlastos." (TUGENDHAT, Ernst. Lições sobre ética. p. 345).

28 VLASTOS, Gregory. Justice and equality. In: BRANDT, Richard B. Social Justice. Englewood Cliffs, NJ: Prentice-Hall, 1962. p. 32, grifo do autor, tradução nossa. 
a contemporaneidade uma discussão sobre "(...) 'desigualdades equitativas' ou 'igualdades desiguais'." ${ }^{29}$, sempre com o objetivo de fundamentar direitos a partir de uma noção de "justiça igualitária" ${ }^{30}$. Com base nos antigos, a relação entre moralidade e mérito pode ser estabelecida por meio de uma gradação entre os homens, de modo que uns são melhores ou piores do que os outros e aquele que é melhor merece, por certo, uma consequência melhor do que a dos piores homens.

No entanto, na história moderna das ideias ocorre justamente o contrário e a igualdade é vista sem exceções, sem mérito ou qualquer tipo de gradação entre as pessoas. Somente a partir da modernidade, a linguagem dos direitos morais passou a ser vista sob a perspectiva do valor absoluto, a ponto de todos possuírem dentro de si um valor intrínseco que nunca poderá ser forjado dos seres humanos. Isso não significa que desigualdades não possam ser permitidas. Vlastos, inclusive, aceita algumas desigualdades, desde que sejam usadas justamente para garantir a igualdade absoluta entre os seres humanos. Para encontrar essas desigualdades justas, ele visa encontrar razões que justifiquem o tratamento diferenciado como uma exceção justa. Diz:

Temos que encontrar razões para os nossos direitos naturais, que serão as únicas razões morais para exceções justas para eles em circunstâncias especiais. (...) um conceito igualitário de justiça pode admitir desigualdades justas, sem inconsistência se, e somente se, ele servir de base para a igualdade dos direitos humanos que também são as bases de direitos desiguais de outros tipos. ${ }^{31}$

Vlastos é um filósofo platônico que estabeleceu uma relação entre igualdade e universalidade a partir da linguagem moderna dos direitos humanos, argumentando que todos os homens devem ser iguais em dignidade e tratados como seres livres e fins em si mesmos, independentemente de qualquer diferença perceptível ou do merecimento de um indivíduo virtuoso com a prática da excelência moral ou do fato de sermos merecedores da bondade ou da maldade. Segundo a resposta dada ao longo da modernidade, o "(...) "valor humano" não

29 VLASTOS, Gregory. Justice and equality. p. 32, tradução nossa.

30 VLASTOS, Gregory. Justice and equality. p. 72, tradução nossa.

31 VLASTOS, Gregory. Justice and equality. p. 40, grifos do autor, tradução nossa. 
é, absolutamente, um "conceito de gradação"."32. Essa é, na verdade, a resposta que as teorias modernas e contemporâneas costumam dar ao desafio cético contido na seguinte pergunta: "Por que todos os seres humanos igualmente, e não apenas, ou basicamente, os merecedores?"33. Porque não se trata de uma questão sobre hierarquia e gradação entre os humanos. Trata-se de um valor absoluto.

Afirma Vlastos: “(...) se há um valor inerente à própria pessoa como um indivíduo integral e único, esse valor não será abrangido pelo mérito ou ser redutível a ele."34. Vlastos, segundo Feinberg, "(...) argumentou que a doutrina de direitos humanos iguais universais pressupõe um conceito de valor humano igual e universal que deve distinguir-se frontalmente da idéia de méritos humanos." ${ }^{35}$. Prossegue Feinberg:

O reconhecimento do "valor humano" de outrem é, sob certo aspecto, extremamente semelhante a (embora não seja absolutamente a mesma coisa) amar uma outra pessoa, pois nenhuma dessas duas coisas depende dos graus que atribuímos aos méritos da outra pessoa. ${ }^{36}$

No fundo, todo programa de fundamentação dos direitos humanos pretende universalizar os direitos ${ }^{37}$ a partir da igualdade absoluta entre os homens, de modo que buscam fundamentar esses direitos a partir de uma vasta e criativa gama de caminhos, conforme afirma Feinberg:

A maioria dos filósofos concorda com seus desafiantes céticos quanto ao fato de que, se há determinados direitos possuídos por todos os homens, independentemente de seus méritos, isso tem que ocorrer porque, apesar de suas várias desigualdades, todos os homens são iguais em algum aspecto de suprema importância moral. Tentando definir qual seja esse aspecto, alguns mencionam outras características de valor; alguns optam por determinadas capacidades naturais, não importando em que grau se tenham efetivado, tais como "racionalidade", ou por vulnerabilidades naturais, tais como a suscetibilidade à dor e sofrimento; outros abandonam inteiramente o mundo empírico em

32 FEINBERG, Joel. Filosofia social. p. 134.

33 FEINBERG, Joel. Filosofia social. p. 133, grifos do autor.

34 VLASTOS, Gregory. Justice and equality. p. 43, grifo do autor, tradução nossa.

35 FEINBERG, Joel. Filosofia social. p. 134, grifo do autor.

36 FEINBERG, Joel. Filosofia social. p. 134, grifo do autor.

37 Feinberg (FEINBERG, Joel. Filosofia social. p. 131) e Baier (BAIER, Annette. Moral prejudices: essays on ethics. Tradução nossa. Cambride, Massachusettes: Harvard University Press, 1994. p. 246.) apontam o direito de não ser torturado como um direito absoluto. 
busca de propriedades transcendentais, uma dignidade intrínseca inerente a todos ser humano como "fins em si mesmas". 38

Nesse diapasão, o caminho que estamos a escolher no presente artigo é criticar as doutrinas dos direitos naturais que se infiltram na linguagem contemporânea dos direitos humanos sob o pretexto do valor absoluto da pessoa humana. Kant é, então, usado para subsidiar uma série de confusões e ambiguidades, de modo que precisamos compreender como o conceito moral de necessidade e valor absoluto é desenhado na filosofia prática de Kant, bem como o trejeito que assume ao se incorporar na linguagem dos direitos humanos.

\section{A herança da tradição liberal}

O discurso kantiano foi e continua a ser amplamente incorporado por juristas e filósofos que estão a pensar e fundamentar os direitos humanos, de modo que esses direitos se perdem em uma leitura prescritiva do fenômeno da reivindicação por direitos que ainda não se encontram positivados em norma jurídica. Os direitos, como direitos naturalmente inatos e válidos para todos humanos, acabam sendo tomados como reflexos do dever, o que será o passo derradeiro para se afirmar o que os direitos "devem ser", mas não o que, efetivamente, são.

Ao pensarmos os direitos humanos como direitos naturais e sob a ótica do valor absoluto, corremos o risco de nos iludirmos com a afirmação de que esses direitos são aqueles que supostamente "todos" os seres humanos possuem em virtude de sua humanidade, ou por causa de sua razão ou racionalidade. Enquanto a maioria dos direitos é entendida como direitos especiais, no caso dos direitos humanos, ocorre um movimento inverso e os direitos escapam e transcendem as obrigações especiais para serem tomados como universais, considerados, portanto, em seu sentido absoluto, como se fossem direitos gerais, ou como se pudessem existir na vida cotidiana dos homens, mesmo quando apartados de uma obrigação específica. Os direitos naturais de valor absoluto não são direitos oriundos de obrigações específicas e, no fundo, constituem o trampolim para algumas ilusões, por meio de generalizações até mesmo absurdas, pois são direitos que geram obrigações e deveres não somente às partes envolvidas, mas 38 FEINBERG, Joel. Filosofia social. p. 136-137, grifos do autor. 
a todas as pessoas do mundo.

\subsection{Kant, o dever - e os direitos?}

Kant preocupou-se excessivamente com o dever moral e, portanto, com aquelas obrigações morais denominadas imperfeitas - obrigações constituídas só por deveres -, razão pela qual levou Feinberg a apontar aquilo que chama a "tese do empobrecimento moral". Feinberg aborda o "empobrecimento moral"39 da filosofia prática de Kant, visto que a principal preocupação do método transcendental se resume exclusivamente ao dever, e não aos direitos. Somente a partir do dever, a motivação da ação pode ganhar o seu valor, um valor absoluto - e é esse discurso transcendental e prescrivisto sobre a moralidade que se junta ao discurso dos direitos naturais para formar o discurso contemporâneo dos direitos humanos. O núcleo duro da investigação moral de Kant é constituído justamente pelos conceitos de boa vontade e, principalmente, de dever, representados nas fórmulas do imperativo categórico. As bases para a fundamentação da moralidade - que serão trazidas para o domínio dos direitos - residem em uma boa vontade e, com a pressuposição de uma boa vontade, Kant apontará uma faculdade no ser humano para agir de acordo com os princípios estabelecidos pela razão. O primeiro objetivo será mostrar que em todo o ser humano se manifesta uma vontade racional e inerente à espécie humana, que é boa em si mesma porque não está necessariamente vinculada ao mundo dos fatos empíricos, ao $a$ posteriori. Afirma Kant sobre a boa vontade: "Neste mundo, e até também fora dele, nada é possível pensar que possa ser considerado como bom sem limitação a não ser uma só coisa: uma boa vontade"40. E prossegue: "assim a boa vontade parece constituir a condição indispensável do próprio fato de sempre dignos da felicidade" 41 .

Se aprofundarmos em Kant, veremos que a vontade é uma capacidade racional do agente moral de agir segundo a representação de regras práticas, que conduzem as escolhas morais do ser humano no campo do agir. Nesse sentido, o conceito de

39 FEINBERG, Joel. Duties, rights, and claims. American Philosophical Quarterly, v. 3, n. 2, p. 144, abr. 1966. Tradução nossa. Disponível em: <http://www.jstor.org/stable/20009200>. Acesso em: 16 mar. 2012.

40 KANT, Immanuel. Fundamentação da metafísica dos costumes. Tradução de Paulo Quintela. São Paulo: Abril Cultural, 1974. p. 203.

41 KANT, Immanuel. Fundamentação da metafísica dos costumes. p. 203. 
boa vontade está intimamente vinculado ao conceito do Dever, como alerta Kant, ao dizer que precisamos "encarar o conceito do Dever que contém em si o de boa vontade"42. O dever, por sua vez, será expresso pelo denominado "imperativo categórico", que constitui as regras morais que Kant considera relevantes para justificar os juízos de bem e mal. O imperativo categórico é o "princípio supremo da moralidade"43 e serve como um fundamento absoluto que não se relativiza na vontade interesseira dos homens, pois é fruto de uma vontade desinteressada, uma vontade pura. As suas formulações destacam a autonomia da vontade, emancipando-se dos fenômenos naturais, ou da heteronomia, para universalizar valores morais, prescrevendo o que é o bem e o mal e determinando o que todo e qualquer ser humano deve fazer no campo moral.

Para desdobrar a sua tese sobre a fundamentação de Kant, Feinberg imagina Nowheresville $^{44}$, um lugar onde as pessoas não possuiriam direitos, só deveres, tal qual o dever de caridade, ao qual não recairia nenhum direito dado em contrapartida. Ao imaginar Nowheresville, alçamos um voo metafísico rumo a uma arquitetônica ideal da moralidade, que passa a ser fundada no âmbito do dever-ser e no modo como as coisas deveriam ser ${ }^{45}$. Diz Feinberg: "(...) nenhuma ação pode ter um tipo supremo de valor - o que Kant chamou de "valor moral" - a não ser que toda a sua força motivadora derivasse do pensamento de que é requerido pelo dever" ${ }^{\prime \prime 6}$.

Feinberg destaca a influência de Kant para as teorias contemporâneas dos direitos, em especial a sua ênfase ao dever e a uma investigação prescritiva. Feinberg aponta, nos anos 90, que o interesse pela linguagem dos direitos é bastante recente, pois, até então, a filosofia moral olhava apenas para o dever. Diz Feinberg:

Houve um tempo há cerca de quarenta anos em que tratados e livros

42 KANT, Immanuel. Fundamentação da metafísica dos costumes. p. 206, grifo do autor.

43 KANT, Immanuel. Fundamentação da metafísica dos costumes. p. 200, grifos do autor.

44 FEINBERG, Joel. The nature and value of rights. Journal of Value Inquiry, v. 4, p. 243, winter 1970. Disponível em: <http://www.law.georgetown.edu/faculty/lpw/documents/ FeinbergNatureandValueofRightsexcerpt.pdf>. Acesso em: 13 mar. 2012.

45 No artigo Modern moral philosophy (1958), Elizabeth Anscombe já apontava os equívocos que acometem a filosofia moral moderna ao destacar que, se, por um lado, os filósofos modernos desprezam a noção de Deus e as determinações de uma lei divina, por outro, se apegam fortemente a uma análise prescritiva do fenômeno moral, que relaciona o dever aos valores morais de bem e mal.

46 FEINBERG, Joel. The nature and value of rights. p. 243, grifos do autor, tradução nossa. 
de filosofia moral estavam esmagadoramente preocupados com os nossos deveres e com o que devemos fazer em geral (estes eram geralmente considerados como equivalente). (...) Mais comumente os capítulos que indicavam os direitos, por outro lado, os desprezavam. Os direitos morais, em vez de serem estranhos ou exóticos, eram pensados para ser lugar-comum, derivado, e trivial. Para ser claro, eles são logicamente correlativos com deveres, mas deveres eram a noção fundamental, e os direitos eram simplesmente uma forma alternativa de falar dos deveres das outras pessoas. ${ }^{47}$

Feinberg aponta como uma falha mortal na filosofia prática kantiana a ausência de mais referência à noção de direitos. Embora até chegue a analisar outros tipos mais mundanos de deveres, como o são os imperativos hipotéticos, Kant não dá tanta importância aos direitos. A sua fundamentação moral centra-se em deveres puros, para os outros e para consigo mesmo, em deveres que independem da correlação a direitos. Muito pouco se tem a falar dos direitos e, em razão disso, o dever, em especial um dever puro, passa a puxar e bancar os fundamentos $a$ priori da moralidade. Os direitos, se muito, só seriam direitos em razão de sua positivação na lei.

Assim, podemos constatar que a análise prescritiva da moralidade tão marcante na filosofia prática de Kant parece, de certo modo, contaminar as discussões e os projetos de fundamentação dos direitos humanos que se valem dos direitos naturais para enfatizar mais o que esses direitos deveriam ser do que propriamente o que são na linguagem ordinária dos seres humanos. Nesse sentido, o passo fulminante de qualquer programa de fundamentação dos direitos humanos será esbarrar no discurso kantiano do valor absoluto e nas doutrinas dos direitos naturais, pois ambos partem do pressuposto de que os homens são livres e possuem direitos estabelecidos em razão de sua igualdade. Tanto um quanto o outro recorrem a um critério interno ao sujeito de direito, um critério a priori e absoluto (que se opõe à autoridade dos critérios externos, como é o caso da sanção jurídica por meio da força física), para fundamentar direitos metafísicos.

\section{2. $O$ direito que temos e o direito que gostaríamos de ter}

A réplica que podemos desferir contra uma abordagem dedutiva dos direitos,

47 FEINBERG, Joel. In Defense of Moral Rights. Oxford Journal of Legal Studies, Oxford, v. 12, n. 2, p. 154, 1992. Tradução nossa. Disponível em: <http://ojls.oxfordjournals.org/ content/12/2/149.citation>. Acesso em: 17 mar. 2012. 
como a que encontramos nos programas fundacionalistas dos direitos naturais e do valor absoluto, diz respeito ao pouco esclarecimento que traz sobre a nomeação deles, em especial a nomeação dos direitos humanos. Esses programas teóricos não nos ajudam a compreender a maneira como os direitos humanos são nomeados e reivindicados na esfera pública por grupos que se constituem como portadores de direitos.

Em razão disso, Cranston foi levado a indagar o seguinte: "[os direitos humanos] são algum tipo de direito positivo ou algum tipo de direito moral, algo que os homens realmente têm ou algo que os homens deveriam ter?"48. Bobbio também incorpora a distinção entre ser e dever-ser: "O problema do fundamento de um direito apresenta-se diferentemente conforme se trate de buscar o fundamento de um direito que se tem ou de um direito que se gostaria de ter." ${ }^{49}$. Cranston dá como resposta à sua própria pergunta a seguinte distinção, que retoma a velha oposição entre direito positivo e direito natural: "Assim como um direito positivo pertence, por definição, ao domínio dos fatos, do que é; portanto, um direito moral pertence, por definição, à categoria do que deveria ser" ${ }^{\prime \prime 0}$. Prossegue:

Dizer que os direitos humanos são direitos morais não é negar que eles são para muitas pessoas direitos positivos, bem como direitos morais. Onde os direitos humanos são defendidos pela lei positiva - onde as pessoas têm o que elas deveriam ter - os direitos humanos são tanto direitos morais quanto direitos positivos. Mas é essencial ter em mente a distinção entre o que é e o que deveria ser, entre o empírico e o normativo, entre o domínio dos fatos e o da moralidade. ${ }^{51}$

Se ficarmos atentos à distinção entre o ser e o dever ser, veremos que toda teoria de direitos humanos é ilusória porque projeta o "direito que se gostaria de ter" sobre o "direito que se tem"; são teorias que não explicam como as pessoas nomeiam cotidianamente os seus direitos, definindo-os simplesmente a partir da dedução metafísica, a partir da ideia de como os direitos deveriam ser. Os direitos humanos deveriam ser gerais, absolutos, universais, inalienáveis, inalteráveis, incondicionais, dentre outros tantos adjetivos que constituem o

48 CRANSTON, Maurice. What are human rights? p. 6, tradução nossa.

49 BOBBIO, Norberto. A era dos direitos. Tradução de Carlos Nelson Coutinho. Rio de Janeiro: Elsevier, 2004. p. 15, grifos do autor.

50 CRANSTON, Maurice. What are human rights? p. 19, grifos do autor, tradução nossa.

51 CRANSTON, Maurice. What are human rights? p. 6, tradução nossa. 
imaginário dos defensores e ativistas dos direitos humanos, bem como as ideias dos seus investigadores.

\section{Ceticismo em relação à dedução dos direitos}

A dedução de um direito que gostaríamos de ter leva-nos, enfim, a considerar os direitos a partir de um plano ideal, definidos a partir do modo como gostaríamos que fossem, como direitos ideais, e não propriamente como direitos efetivos ou vigentes. Poderíamos, então, falar em direitos naturais, isto é, em direitos a priori e iguais para todos os seres humanos concedidos pela natureza. Poderíamos, ainda, falar em valor absoluto e em direitos universais em razão da nossa humanidade. Mas não poderíamos dizer que temos uma razão - ao menos não uma razão no sentido forte do termo - regulando a posse dos direitos, e este é o caso dos direitos humanos. Temos, se muito, uma razão "relacional" entre pessoas, uma razão inserida em um contexto no qual os seres humanos atribuem direitos e deveres uns aos outros.

Diante da ausência de uma razão "forte" para a fundamentação dos direitos, resta, pois, mostrar que o grande problema da tradição liberal dos direitos é que a sua investigação filosófica logo se perde em uma reflexão sobre o que os direitos "deveriam ser", em especial o que os direitos humanos deveriam ser ou quais são os direitos que deveríamos ter ou possuir para sermos considerados seres humanos. "O papel dos direitos no raciocínio moral é principalmente justificar a ação e as restrições sobre a ação em vez de descrever estados de coisas" ${ }^{\prime 52}$. Desde o Iluminismo, e em especial após a Segunda Guerra Mundial, a metodologia empregada para a análise dos direitos humanos é, no fundo, o principal obstáculo a dificultar não apenas nossa percepção sobre a natureza desses direitos, mas, principalmente, a dificultar a efetivação dos direitos humanos na vida prática das pessoas. As dificuldades residem na metodologia empregada na análise desses direitos, posto que a tradição filosófica esbarra em uma abordagem prescritiva dos direitos, que até pode funcionar para alguns casos, como aqueles rigorosamente estipulados pela lei, mas que, certamente, falha na abordagem daqueles direitos reivindicados a partir do fenômeno social, moral e político.

52 JONES, Peter. Rights: issues in political theory. Tradução nossa. Hampshire: Palgrave/Macmillan Press, 1994. p. 47, grifos do autor. 
Quando falamos em direitos humanos, falamos também em direitos que deveriam ser de todas as pessoas, que todos deveriam possuir em razão de sua natureza, e assim por diante. Os direitos humanos deveriam ser absolutos e universais, válidos para todos os homens independentemente de qualquer legislação específica situada no tempo e no espaço. No entanto, este não é o caso, pois, nem os direitos humanos, nem a moralidade, são a priori e absolutos, embora não neguemos o fato de que gostaríamos que esses direitos fossem, na realidade, direitos universais.

No âmbito da positivação do direito, a Convenção de Viena de 1993 é o documento que talvez melhor represente as dificuldades envolvidas na problemática da universalidade desses direitos, pois embora se comprometa explicitamente com a promoção e o respeito ao caráter universal dos direitos humanos, também relativiza esta tese ao destacar a necessidade de observarmos as particularidades e as regionalidades dos diversos contextos de um mundo global, diversificado e plural.

Em paralelo à Convenção de Viena e em oposição aos programas metafísicos de direitos humanos, autores como Rabossi constataram, nos anos 90, que a postura fundacionalista empregada desde o final da Segunda Guerra "(...) sustenta que os direitos humanos necessitam de fundamentação, isto é, um suporte ou uma justificação racional." ${ }^{\prime 3}$ - e é contra essa postura fundacionalista que elenca severas críticas aos projetos fundacionalistas, especialmente contra Alan Gewirth ${ }^{54}$ e Santiago $\mathrm{Nino}^{55}$, dois importantes autores de direitos humanos que intentam fundar as bases dos direitos humanos em um critério absoluto.

Gewirth, por exemplo, afirma: "(...) que certos direitos podem ser mostrados como absolutos. Mas, primeiro, o conceito de um direito absoluto deve ser esclarecido" ${ }^{56}$. Para esclarecer esse conceito, Gewirth procura exemplos de direitos que não podem ser substituídos, direitos

53 RABOSSI, Eduardo. La teoría de los derechos humanos naturalizada. Tradução de Matilde Vivancos Machimbarrena. Revista del Centro de Estudios Constitucionales, Madrid, n. 5, p.160, jan.-mar. 1990. Tradução nossa. Disponível em: <http://pt.scribd.com/doc/68557384/ Rabossi-La-Teoria-de-LosDerechos-Humanos-Naturalizada>. Acesso em: 23 fev. 2012.

54 GEWIRTH, Alan. Are there any absolute rights? The Philosophical Quarterly, Blackwell Publishing, Oxford/Malden, v. 31, n. 122, p. 1-16, jan. 1981. Disponível em: <http://www.jstor.org/stable/2218674>. Acesso em: 29 mar. 2012.

55 NINO, Carlos Santiago. Ética y derechos humanos: un ensayo de fundamentación. Barcelona: Ariel, 1989. 494p.

56 GEWIRTH, Alan. Are there any absolute rights? p. 2, tradução nossa. 
que, ao entrarem em conflito com outros direitos, devem sempre prevalecer. Ele afirma o seguinte: "Um direito é absoluto quando não pode ser substituído em qualquer circunstância, de modo que ele nunca pode ser justificadamente infringido e deve ser cumprido sem qualquer exceção" ${ }^{57}$. Para comprovar essa afirmação, Gewirth imagina um grupo de terroristas que ameaça explodir uma bomba nuclear e matar todas as pessoas do mundo, exceto se um determinado político torturar a sua mãe até a morte. Haveria um direito absoluto da mãe em não ser torturada até a morte pelo filho? - pergunta-se Gewirth, ao destacar que a humanidade seria dizimada se não fosse assim, ao mesmo tempo em que dá uma resposta afirmativa: "Um direito de uma mãe não ser torturada até a morte por seu próprio filho está além de qualquer compromisso. É absoluto."58.

Santiago Nino, por sua vez, propõe uma nova abordagem do conceito de direitos morais a partir daquilo que chamou "(...) “construtivismo ético" (também denominado 'formalismo' ou 'conceitualismo', embora estes rótulos não sejam equivalentes)" ${ }^{\prime \prime 2}$. Com isso, intenta uma reconstrução dos direitos naturais a partir de uma moral crítica ou ideal, derivando princípios éticos para conseguir estruturar uma fundamentação intrínseca ao direito: "(...) as razões morais devem operar não somente por trás do direito senão também, pelo que acabo de dizer, 'através' do direito"60. Desse modo, julga fundamentar direitos humanos a partir de uma noção forte de racionalidade, como se os direitos humanos fossem realmente universais e absolutos.

Desde as críticas de Rabossi até o atual cenário do mundo contemporâneo, vários autores perceberam as contradições em se defender a universalidade dos direitos humanos e propuseram algumas variáveis relativistas no anseio de destacar a pluralidade e a diversidade cultural. Jack Donnelly é um dos autores que propõe gradações entre as posturas relativista e universalista, no intuito de reconhecer o relativismo cultural sem descartar a noção de universalidade contida nos direitos humanos. Donnelly defende a ideia de uma universalidade relativa para os direitos humanos: "os direitos humanos são "relativamente universais" no mundo contemporâneo"61. Continua:

57 GEWIRTH, Alan. Are there any absolute rights? p. 2, grifo do autor, tradução nossa.

58 GEWIRTH, Alan. Are there any absolute rights? p. 8, tradução nossa.

59 NINO, Carlos Santiago. Ética y derechos humanos. p. 92, grifos do autor, tradução nossa.

60 NINO, Carlos Santiago. Ética y derechos humanos. p. 124, tradução nossa.

61 DONNELLY, Jack. Universal human rights in theory and in practice. Tradução nossa. 3. ed. Ithaca: 
A universalidade dos direitos humanos é relativa no mundo contemporâneo. As particularidades da sua aplicação são relativas à história, à política, à cultura e às decisões particulares. No entanto, ao nível do conceito, tal como especificado na Declaração Universal, os direitos humanos são universais. A formulação "relativamente universal" é, assim, particularmente apropriada. A relatividade modifica - opera dentro dos limites estabelecidos da - a universalidade do corpo de direitos humanos internacionalmente reconhecidos como interdependentes e indivisíveis. ${ }^{62}$

Contudo, propostas como a de Donnelly, em nossa opinião, não esclarecem o que, de fato, são os direitos humanos e, no fundo, só prosseguem com as ilusões que já atormentavam os projetos de fundamentação de direitos humanos do Iluminismo. Seguindo as críticas de Rabossi, é preciso mostrar, pois, que não estamos dizendo que os direitos a priori e absolutos não existem para as pessoas que acreditam neles, ou que devemos abandonar a discussão sobre direitos universais devido a sua carência de justificação racional. O que queremos deixar claro é que a metodologia dedutiva oriunda do Iluminismo, e reafirmada após a Segunda Guerra, já não dá mais conta da explicação dos direitos humanos no mundo contemporâneo.

A investigação sobre os direitos não está submetida e restrita a uma "análise conceitual"63 sobre o que os direitos deveriam ser, nem pode ser fundamentada a partir de um procedimento dedutivo. Aúnica alternativa que nos resta é investigar o que são esses direitos, principalmente ao descrevermos o comportamento verbal das pessoas ao se referirem a eles. Estamos, portanto, a destacar a necessidade de uma virada metodológica na análise dos direitos humanos, uma virada de cunho cético, segundo a qual vale mais a pena descrever e compreender como os direitos são enunciados do que em ditar como eles deveriam ser. A nossa preocupação diz respeito à descrição das maneiras pelas quais as pessoas se referem aos direitos extralegais (como o são alguns direitos humanos), aos valores de bem e mal e às obrigações e aos deveres que recaem sobre nossas cabeças,

Cornell University Press, 2013. p. 93.

62 DONNELLY, Jack. Universal human rights in theory and in practice. p. 105, tradução nossa.

63 Sobre os limites da "análise conceitual" dos direitos: LEITER, Brian. Legal realism and legal positivism reconsidered. Ethics, v. 111, n. 2, p. 278-301, jan. 2001a. Disponível em: <http://www.jstor.org/stable/10.1086/233474>. Acesso em: 20 dez. 2011. Ver também: LEITER, Brian. Legal realism, hard positivism, and the limits of conceptual analysis. In: COLEMAN, J.L. (Ed.). The Postscript: essays on Hart's postscript to the concept of law. Oxford: Clarendon Press, 2001b. 
conforme aconselha Feinberg:

Se nos concentrarmos em toda atividade da reivindicação, que é pública, familiar e aberta a nossa observação, do que nos concentrarmos apenas em seu resultado, poderemos aprender mais a respeito da natureza genérica dos direitos do que jamais poderíamos esperar aprender de uma definição formal, mesmo que fosse possível formular uma. ${ }^{64}$

De modo algum a nossa pretensão é a nomeação propriamente dita dos direitos - como se pudéssemos determinar quais são, na realidade, os direitos essenciais a todo ser humano, como se o homem possuísse direitos absolutos e universais; direitos que lhe são inerentes em razão de sua humanidade; direitos imprescritíveis, inalienáveis e irrenunciáveis. Nesse sentido, estamos com Mackie que foi enfático ao negar a existência de direitos a priori e absolutos. Diz ele: "(...) eu defenderia duas teses negativas, que os direitos específicos não podem ser determinados a priori, em termos gerais, e que todos os direitos reconhecidos não devem ser absolutos"65. Com isso, podemos verificar a decadência dos programas fundacionalistas de direitos humanos que ainda não perceberam que "(...) o mundo mudou e que o fenômeno dos direitos humanos converte o fundamentalismo dos direitos humanos em passado de moda e inaplicável"66. Até porque o mundo não iria se ajustar às ambições de uma teoria ideal dos direitos humanos.

\section{CONSIDERAÇÕES FINAIS}

Uma postura mais descritivista ${ }^{67}$ - que aqui podemos chamar de "cética"68 - não nega que as pessoas, assim como uma série de programas fundacionalistas de direitos humanos, afirmam e reafirmam que os seres humanos possuem direitos absolutos, universais, imprescritíveis, etc. Cabe, pois, descrever e procurar compreender como esses adjetivos concordam com a expressão "direitos

64 FEINBERG, Joel. Filosofia social. p. 99.

65 MACKIE, John Leslie. 1977. Ethics: inventing right and wrong. Tradução nossa. Harmondsworth: Penguin, 1990. p. 174, grifo do autor.

66 RABOSSI, Eduardo. La teoría de los derechos humanos naturalizada. p. 174, tradução nossa.

67 Nesse sentido, o objetivo de Hart é "(...) apresentar uma teoria do direito que fosse ao mesmo tempo geral e descritiva. (...) Minha exposição é descritiva no sentido de que é moralmente neutra e não tem fins de justificativa (...)" (HART, 2009, p. 309, grifo do autor).

68 Sobre a relação entre direitos, moral e ceticismo, ver: BLUMENSON, 1996, p. 523-576; CAMPBELL, 2001; NIELSEN, 1968, p. 573-594; 1996; STRAWSON, 2008. 
humanos". Segundo o procedimento descritivo, basta observar que as perspectivas em torno dos direitos humanos, seja a partir de pessoas corporificadas no senso comum, seja a partir de teorias e investigações sobre os fundamentos dos direitos humanos, atribuem um sentido "absoluto" aos termos da linguagem que empregam para falar daqueles direitos que são tão especiais a nós mesmos, seres humanos. No nosso dia a dia, afirmamos, por exemplo, possuir direitos que não são propriamente direitos legais e não se originam de uma alçada juridicamente soberana. Afirmamos possuir direitos naturais ou mesmo direitos morais, que nos pertencem em razão de nossa natureza racional e daquilo que nos constitui como seres humanos.

Observem que, em nenhum momento, uma postura cética perante os direitos poderá dizer o que devem ser os direitos humanos, muito menos poderá afirmar que são direitos absolutos, pois essa é uma tarefa que não diz respeito à perquirição moral dos direitos, no sentido de que à investigação compete somente descrever e explicar o modo pelo qual as pessoas se referem aos direitos denominados humanos. Disso decorrem vários desafios quanto à definição dos direitos e o maior deles, no qual estão envolvidos todos os projetos fundacionalistas, diz respeito à própria concepção de moralidade, que é uma moralidade tomada em um sentido absoluto, a partir do qual os direitos humanos são deduzidos de uma natureza morta. O problema é que esse sentido absoluto não sustenta os projetos de fundamentação dos direitos humanos, nem as concepções metafísicas de moralidade, embora seja perceptível a presença do discurso universalista de Kant e das doutrinas dos direitos naturais na discussão contemporânea dos direitos humanos. Ainda se apregoam direitos para os seres humanos em razão de sua própria natureza; direitos inalienáveis, imprescritíveis, dentre tantos outros adjetivos que almejam universalizar esses direitos e torná-los absolutos.

\section{REFERÊNCIAS DAS FONTES CITADAS}

ANSCOMBE, G. E. M. Modern Moral Philosophy. Philosophy, v. 33, n. 124, p. 1-19, jan. 1958. Disponível em: < http://www.jstor.org/stable/3749051>. Acesso em: 21 maio 2012.

BAIER, Annette. Moral prejudices: essays on ethics. Cambride, Massachusettes: Harvard 
University Press, 1994. 369p.

BEITZ, Charles. What human rights mean. Daedalus, On International Justice, v. 132, n. 1, p. 36-46, winter 2003. Disponível em: <http://www.jstor.org/stable/20027821>. Acesso em: 12 jun. 2012.

BLUMENSON, Eric. Mapping the limits of skepticism in law and morals. Texas law review, v. 74, n. 3, p. 523-576, fev. 1996. Disponível em: < http://heinonline.org/HOL/Print?handle=hein. journals/t|r74\&div=32\&collection=journals\&set_as_cursor=6\&men_tab=srchresults $>$. Acesso em: 19 maio 2012.

BOBBIO, Norberto. A era dos direitos. Tradução de Carlos Nelson Coutinho. Rio de Janeiro: Elsevier, 2004.

BROWN, Stuart M. Inalienable Rights. The Philosophical Review, v. 64, n. 2, p. 192-211, abr. 1955. Disponível em: <http://www.jstor.org/stable/2182587>. Acesso em: 18 maio 2012.

CAMPBELL, Tom; EWING, Keith; TOMKINS, Adam. Sceptical Essays on Human Rights. New York: Oxford University Press, 2001. 423p.

CRANSTON, Maurice. What are human rights? London: Bodley Head, 1973. 170 p.

DONNELLY, Jack. Universal human rights in theory and in practice. 3. ed. Ithaca: Cornell University Press, 2013. 320p.

FEINBERG, Joel. Duties, rights, and claims. American Philosophical Quarterly, v. 3, n. 2, p. 137-144, abr. 1966. Disponível em: <http://www.jstor.org/stable/20009200>. Acesso em: 16 mar. 2012.

The nature and value of rights. Journal of Value Inquiry, v. 4, p. 243-257, winter 1970. Disponível em: <http://www.law.georgetown.edu/faculty/lpw/documents/ FeinbergNatureandValueofRightsexcerpt.pdf>. Acesso em: 13 mar. 2012.

Filosofia social. Tradução de Alzira Soares da Rocha e Helena Maria Camacho. Rio de Janeiro: Zahar, 1974. 178p.

In Defense of Moral Rights. Oxford Journal of Legal Studies, Oxford, v. 12, n. 2, p. 149-169, 1992. Disponível em: < http://ojls.oxfordjournals.org/content/12/2/149.citation >. Acesso em: 17 mar. 2012.

FINNIS, John. 1980. Lei natural e direitos naturais. São Leopoldo: Unisinos, 2007. 403p.

FRANKENA, William K. Natural and inalienable rights. The Philosophical Review, v. 64, n. 2, p. 212-232, abr. 1955. Disponível em: <http://www.jstor.org/stable/2182588>. Acesso em: 30 mar. 2012.

GEWIRTH, Alan. Are there any absolute rights? The Philosophical Quarterly, Blackwell Publishing, 
Oxford/Malden, v. 31, n. 122, p. 1-16, jan. 1981. Disponível em: <http://www.jstor.org/stable/2218674>. Acesso em: 29 mar. 2012.

HART, Herbert Lionel Alphonsus. 1955. Are There Any Natural Rights? The Philosophical Review, Duke University Press, v. 64, n. 2, p. 175-191, abr. 1955. Disponível em: <http://www.jstor.org/ stable/2182586>. Acesso em: 12 fev. 2012.

O conceito de direito. São Paulo: Martins Fontes, 2009. 399p.

JONES, Peter. Rights: issues in political theory. Hampshire: Palgrave/Macmillan Press, 1994. 258p.

KANT, Immanuel. Fundamentação da metafísica dos costumes. Tradução de Paulo Quintela. São Paulo: Abril Cultural, 1974. p. 195 - 256 (Os Pensadores)

LEITER, Brian. Legal realism and legal positivism reconsidered. Ethics, v. 111, n. 2, p. 278-301, jan. 2001a. Disponível em: <http://www.jstor.org/stable/10.1086/233474>. Acesso em: 20 dez. 2011.

Legal realism, hard positivism, and the limits of conceptual analysis. In: COLEMAN, J.L. (Ed.). The

Postscript: essays on Hart's postscript to the concept of law. Oxford: Clarendon Press, 2001b.

MACDONALD, Margaret. Natural Rights. Proceedings of the Aristotelian Society, New Series, v. 47, p. 225-250, 1946-1947. Disponível em: <http://www.jstor.org/stable/4544427>. Acesso em: 6 jun. 2012.

MACKIE, John Leslie. Ethics: inventing right and wrong. Harmondsworth: Penguin, 1990. 249p.

NIELSEN, Kai. Naturalism without foundations. New York: Prometheus Books, 1996. 607p.

Scepticism and human rights. Monist, v. 52, n. 4, p. 573-594, out. 1968.

NINO, Carlos Santiago. Ética y derechos humanos: un ensayo de fundamentación. Barcelona: Ariel, 1989. 494p.

RABOSSI, Eduardo. La teoría de los derechos humanos naturalizada. Tradução de Matilde Vivancos Machimbarrena. Revista del Centro de Estudios Constitucionales, Madrid, n. 5, p.159-175, jan.mar. 1990. Disponível em: <http://pt.scribd.com/doc/68557384/Rabossi-La-Teoria-de-Los-DerechosHumanos-Naturalizada>. Acesso em: 23 fev. 2012.

RITCHIE, David George. Natural rights: a criticism of some political and ethical conceptions. Bristol: Thoemmes Press, 1998. 304p.

STRAUSS, Leo. Natural rights and history: a cogent examination of one of the most significant issues in modern political and social philosophy. Chicago / London: The University of Chicago Press, 1965. 326p.

STRAWSON, Peter Frederick. Ceticismo e naturalismo: algumas variedades. São Leopoldo: Unisinos, 2008. 114 p.

TUGENDHAT, Ernst. Lições sobre ética. 5. ed. Petrópolis: Vozes, 2003.

VLASTOS, Gregory. Justice and equality. In: BRANDT, Richard B. Social Justice. Englewood Cliffs, NJ: Prentice-Hall, 1962. p. 31-72.

302 Recebido em: abril/2016 Aprovado em: agosto/2017 Disponível EM: www.univali.br/periodicos 